\title{
Music sight-reading expertise, visually disrupted score and eye movements.
}

\author{
Patricia Arthur \\ University of New South Wales, Sydney, Australia \\ p.arthur@unsw.edu.au
}

\author{
Sieu Khuu \\ University of New South Wales, \\ Sydney, Australia
}

\author{
Diana Blom \\ Western Sydney University, \\ Sydney, Australia
}

Previous studies have shown that performance at a defined level of music sight-reading for pianists $\left(6^{\text {th }} \mathrm{Grade}\right)$ is predictive of eye movement patterns (Waters, Townsend, \& Underwood, 1998) and that such patterns resemble those of text reading experts (Furneaux \& Land, 1999, Sloboda, 1974, Truitt, Clifton, Pollatsek, \& Rayner, 1997; Wolf, 1976). These patterns include fewer fixations of shorter duration and fewer regressive saccades that allows for more efficient processing of visual information per fixation. However, little is known about how expertise might affect eye movement patterns when the score has been visually disrupted using notational features that are unexpected or outside conventional presentation. The current project examined the effect of altering features of the music score on eye movement patterns of expert and non-expert music sight-readers. Participants read, by sight, specifically composed musical excerpts. These pieces were then re-presented with the bar-lines removed, disrupted spacing and unpredictable beaming directions. Fixation and saccade characteristics were measured and compared between the two performances. It was expected that expert music sight-readers would be most affected when the score was disrupted as they would be less capable of grouping notes into familiar, single units for efficient visual processing. Expert sight-readers performed significantly faster than non-experts in both conditions: $\mathrm{p}<0.0001$. Saccadic latency increased significantly for experts in the disrupted condition: $\mathrm{p}=0.03$. Non-experts increased slightly, but not significantly. This suggests that the disruption of visual expectation was sufficient to cause a lengthening of saccade programming in the experts - an indication of interference with the 'chunking' process. The resultant EM patterns for the non-experts demonstrated heightened non-expert behaviours: increased fixations of shorter duration.

Keywords: eye movement, eye tracking, saccades, reading, fixation duration, music sight-reading, sight-reading expertise, music cognition.

\section{Introduction}

All cultures enjoy music, but only some write it down (Huron, 2001). In order to 'read' the music, one has to be able

Received May 17, 2016; Published October 15, 2016.

Citation: Arthur, P., Khuu, S. \& Blom, D. (2016). Mu-

sic sight-reading expertise, visually disrupted score and eye movements. Journal of Eye Movement Research, 9(7):1, 1-12.

Digital Object Identifier: $10.16910 /$ jemr.9.7.1

ISSN: $1995-8692$

This article is licensed under a Creative Commons Attribution 4.0 International license. (oc) $\mathrm{Er}$ to see it, contextualize it and then reproduce it on an instrument of choice - not unlike reading text. Successful text reading requires efficient eye movements and the relationship between eye movement patterns and cognitive processing is well documented (Ashby, Rayner \& Clifton, 2005: Balota, Pollatsek, \& Rayner, 1985; Binder, Pollatsek, \& Rayner, 1999; Dee-Lucas, Just, Carpenter, \& Daneman, 1982; Ehrlich \& Rayner, 1981; Fleisher, 1986; Gobet, Lane, Croker, Cheng, Jones, Oliver, \& Pine, 2001; Juhasz \& Rayner, 2003; Just \& Carpenter, 1976; Kennison \& Clifton, 1995; Meseguer, Carreiras, \& Clifton, 2002, Miellet and Sparrow, 2004; Underwood, Hubbard, \& Wilkinson, 1990). As a consequence, eye movement patterns can expose difficulties in reading comprehension (Rayner, Chace, Slattery, \& Ashby, 2006; Underwood, Hubbard, \& Wilkinson, 1990). 
Similarly, eye movements can reveal visual processing expertise. Object details can be clumped or 'chunked' into recognizable groups or patterns. An 'expert' in a particular domain, reading text for example, is characterized by the ability to chunk elements of that domain into smaller units for more efficient processing (Ashby et al., 2005; Gobet et al., 2001; Heller, 1982; Kowler, 2011; Legge, 2007; Meseguer et al., 2002; Rayner, 1998; Rayner et al., 2006; Truitt et al., 1997; Underwood et al., 1990). It is a direct result of extensive, structured domain knowledge and is achieved by employing fewer fixations of shorter duration relative to more non-expert sight-readers (Underwood et al., 1990). The resultant increase in speed of performance is characteristic of expertise generally (Bilalic, Langner, Ulrich, \& Grodd, 2011; Ericsson, Krampe, Tesch-Romer, 1993; Ericsson, Roring, \& Nandagopal, 2007; FarringtonDarby \& Wilson, 2006; Gauthier \& Bukach, 2007).

Similar patterns have been found when researching the eye movements of musicians as they read music Furneaux \& Land, 1999; Goolsby, 1987; Kinsler \& Carpenter, 1995; Schmidt, 1981; Sloboda 1974, 1977; Truitt et al., 1997; Wolf, 1976; Wurtz, Mueri, \& Wiesendanger, 2009). Sightreading is a subset of music-reading skills where prompt performance of a piece of music is required when read directly from notated music, known as the score. Sight-reading differs from reading music in other practice or performance contexts as it requires the musician to reproduce the music with little to no prior experience of the piece to be played. It is a skill that is invaluable for repetiteurs, accompanists and a very useful skill-set for piano teachers, performers and musicians generally. Researchers and musicians alike, vary in the definition of sight-reading. Some describe sight-reading as only occurring the first time an unfamiliar piece of music is played while others consider that familiarization with a piece before playing would also constitute a sight-reading task (Lehmann \& McArthur, 2002).

Musicians exhibit a vast range of ability in sight-reading. Past research has shown that some musicians attain 'expert' status in this domain. It is suggested that sight-reading is a matter of skilled pattern recognition (Wolf, 1976) so that the better one becomes at recognizing the patterns, the more 'expertise' one should demonstrate in performing a sight-reading task (Kinsler \& Carpenter, 1995). Evidence for music sight-reading expertise has been found in the eye movement patterns of musicians reading score and these are similar to those found in text reading. Specifically, the ability to 'chunk' groups of notes into a single unit for processing rather than reading each note individually (Sloboda 1974, Wolf 1976, Truitt et al., 1997, Furneaux and Land 1999) and the disruption of fixation patterns when unexpected harmonic notes are introduced (Sloboda, 1987).
It is also known that more expert sight-readers can exhibit what has become known as 'proof-reader error'. This occurs when a note that is not part of the harmonic language of a piece is presented in the score, but an incorrect note is played that conforms to the overall harmonic structure rather than the note that is written (Sloboda, 1976; Wolf, 1976). This points towards further evidence of the expert's ability to 'chunk' groups of notes rather than reading each note individually. Less experiences sight-readers tend not to make the same errors.

When musical score was simplified, the EM pattern changed (Servant \& Baccino, 1999). However, in this study, these were not visual manipulations of the score, but simplifications. As the original version, known as 'first pass', had already been performed, it might be expected that the EMs would be different as it is the 'second pass' which is known to be different (Goolsby, 1994) without the additional variation of a simplified score. Also, there was no guarantee that the subjects were not already familiar with the piece. Consequently, the results of this and many of the earlier studies are far from conclusive (Madell \& Hebert, 2008).

More recently, researchers have shown that when dynamic markings on the score are mismatched with the music being played, different EM patterns are deployed by expert and non-experts (Drai-Zerbib \& Baccino, 2014). However, this study did not deal strictly with sight-reading in that the subjects were not required to perform the music on an instrument, but rather was a test of domain specific crossmodal match/mismatch competence. Nevertheless, it does demonstrate that visual aspects of the score could result in EM differences based on expertise.

What has yet to be investigated in detail is how musicians' EMs responds when visual features of the music other than harmonic are disrupted in a simple sight-reading task. For example, the physical appearance of the notes on the score page contain temporal information, that is, notes are spaced roughly according to their duration and bar lines demarcate groups of notes according to the duration and number qualities indicated in the time signature at the beginning of the piece. fMRI studies have shown that an area of the brain involved in spatial processing, the left occipital cortex, is activated when reading music but not when reading text and is thought to suggest that the distances between the notes are a relevant part of music reading processing in relation to pitch (Fourie, 2004). It is not unreasonable to suggest that spacing between the notes is involved in the temporal processing of music notation. In addition, the note stems or beams frequently encode pitch information by being directed above or below the note depending on their position on the stave. Therefore, the alteration of these expected parameters, within the context of 
conventional music notation, may be expected to alter fixation patterns in a similar way to unexpected harmonic structures.

In relation to text reading, it is known that saccadic latency increases with uncertainty with an average value of $250 \mathrm{~ms}$ (Cameron, 1995), these findings were for adults with text reading expertise and did not examine novice readers under the same conditions. Given that expert text readers fixate less frequently and for shorter periods of time (Underwood, et al., 1990) with the opposite being true for nonexperts (Rayner et al., 2006), creating uncertainty in music score might be expected to alter fixation patterns, as fixations lengthen when targets are disrupted for text reading (Staub, 2013). Changing spacing in text affects word identification and manifests in saccade programming as increased latency resulting in shorter and/or cancelled saccades and longer fixations (Perea \& Acha, 2009). Decreased reading rate is also associated with spacing manipulations as is an increase in regressive saccades (Rayner, Fischer, \& Pollatsek, 1998). Not only is spacing important, but also phrasing has been shown to aid comprehension in speech and syntax (Restle, 1972). What is yet to be investigated, is whether a similar eye movement response occurs when sight-reading music and whether this may be modulated by expertise.

This study investigated the response in eye movements patterns observed in expert and non-expert music sightreaders when features of the music's notational structure are unexpectedly changed by the removal of bar lines, alteration of stem redirection and variation of the inter-note spacing. The study findings help to expand our understanding of the role that visual expectations play in the visual processing expertise in music sight-reading in terms of working memory capacity, cross-modal integration of sensory information and peripheral crowding of visual stimuli.

\section{Hypothesis}

That both groups will show some disruption to their eye movement patterns when sight-reading a visually disrupted score, but such changes will be specific to their level of visual processing expertise.

\section{Participants \\ Methods}

Ethics approval was granted by an Australian University Advisory Committee. Participants were drawn from that university's student body and reimbursed for their time. Study inclusion was based on the ability to play a short musical excerpt as it appeared on the recruitment poster, (see Figure 1a). The participants self-selected based on this criterion. All subjects were able to resolve N5 print at a distance of $60 \mathrm{~cm}$. An expert music sight-reader was defined as being able to perfectly or near perfectly perform a $6^{\text {th }}$ Grade AMEB sight-reading examination piece on piano. This level had previously been shown to elicit expertise in eye movements (Waters et al. 1998). A total of 20 people participated in the study -9 were assigned to the expert sight-reader group and 13 to the non-expert sightreader group according to the $6^{\text {th }}$ grade criteria. All participants were aged between 18 and 21 years of age.

\section{Stimulus}

The current study adopted a sight-reading definition based on having no familiarization of the music to be played and with pre-reading actively discouraged. Ten, 4-bar melodies were individually composed, (see Figure 1a). Each melody was written in the treble clef, to be played by the right hand and limited to white notes only. Identical rhythmic components were used for each in largely non-identical combinations and differing melodic content. These comprised minims, crotchets, quavers, dotted quavers, semiquavers and crotchet and quaver rests.

Four pianists were questioned to elicit an approximate viewing distance of music when placed at a standard upright piano. $60 \mathrm{~cm}$ was then chosen as the testing distance: the range was from 30 to $60 \mathrm{cms}$, with 3 values between 50 and $65 \mathrm{~cm}$.

In order to only examine the effect of the disruption of the score and other visual cues on eye movement patterns, the music stimulus was presented with no blur and at a size equivalent to an optotype of N10. This size has been shown to fall comfortably within the Critical Print Size (CPS) for text reading, a range of letter sizes for which eye movements can be executed at their most efficient (Legge, $2007)$ and is approximately equivalent to a 10/72" (3.5 $\mathrm{mm})$ letter when viewed at $14 "(35.5 \mathrm{~cm})$. The note head size was adjusted to yield the same angular subtense at the eye when viewed at $60 \mathrm{~cm}$, that is, approximately $5.9 \mathrm{~mm}$.

\section{Procedure}

Eye movement data was collected using the Arrington Research 'ViewPoint' USB220 eye tracker, the sampling rate being $220 \mathrm{frames} / \mathrm{second}$. The images were generated using a custom written programme for MATLAB (Version $2014 \mathrm{~b}$, image processing toolbox ${ }^{\mathrm{TM}}$ ) and presented on a linearized 27-inch Mitsubishi Diamond Pro monitor driven at a frame rate of $80 \mathrm{~Hz}$. The tracker was driven by a Hewlett Packard 'Elitebook 8470p' PC (Intel Core i5 2.60GHz processor/8.00GB RAM/16-bit Operating System).

The apparatus consisted of a single infrared camera mounted on a chin and headrest assembly that was mounted on an instrument table. The table was set so that 
the viewing distance to the screen was $60 \mathrm{~cm}$. The participant's height was carefully aligned using a canthus mark that was level with the centre of the computer screen. The camera was then calibrated according to the manufacturer's instructions. Once calibration was successfully performed, a practice session was performed in order for the participant to become familiar and comfortable with the testing process: 4 seconds after a tone sounded, the music stimulus would appear on the computer screen. Participants were instructed to start playing the piece as soon as it appeared on the screen, as quickly and as accurately as possible, without looking down at the hand, without prereading and without stopping regardless of errors. After the participant finished playing, a visual noise patch was presented on the screen. The participant was instructed to fixate on it to eliminate any afterimages that may have been generated by the test stimulus. Sufficient time was given to re-orientate the hands into position by touch between presentations. After 6 trials, the full procedure was undertaken, following the same procedure as the practice session. While it is known that preventing visual feedback in a sight-reading task can increase errors in performance (Banton, 1995), the pieces in the present study were written in the treble clef for white keys only, within an octave span and the subjects were permitted to reposition their hands correctly between trials. Therefore, it was not considered to be difficult to complete without visual reinforcement; particularly as the subjects had self-selected their participation in the study based on their ability to sightread the reference piece on the recruitment poster.

It was necessary to ensure that only EMs involved in the reading of the music were included in the analysis. Variations in the time to start playing after seeing the stimulus, differences in the cessation of relevant EMs towards the end of the piece and inconsistent times in ending recording sequence after playing had ceased all needed to be eliminated. Therefore, the time that playing commenced, T1, through to the time that playing ceased at the end of bar 3 , $\mathrm{T} 2$, was used as the sound window for analysis. The location of $\mathrm{T} 1$ and $\mathrm{T} 2$ was determined using Fleximusic ${ }^{\mathrm{TM}} \mathrm{Au}-$ dio Editor. The sound files were imported and the points on the wave file for $\mathrm{T} 1$ and $\mathrm{T} 2$ were determined by first filtering for noise and then manually marking the location of $\mathrm{T} 1$ and $\mathrm{T} 2$. This process was found to be repeatable to within 0.05 second. Once T1 and T2 were known in relation to the length of the sound file, it was then possible to calculate the number of samples between points $\mathrm{T} 1$ and subT2. Therefore, EM parameters calculated between T1 and $\mathrm{T} 2$ pertain only to the time period of interest: when the music was being read.

Participants sight-read the 9 specifically composed musical excerpts of 4 bars duration (see Figure 1a). In order to minimize any possible familiarity with the pieces, each normal piece and its disrupted counterpart were not presented consecutively. Rather, all 9 pieces in the normal form were played first, followed by the 9 disrupted forms of the score (see Figure 1b). Fixation and saccade characteristics were measured and compared between the normal and disrupted score condition performances, each from $\mathrm{T} 1$ to $\mathrm{T} 2$.

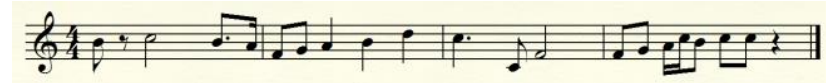

Figure $1 a$

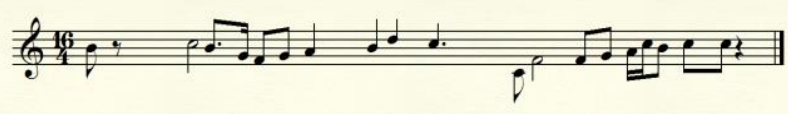

Figure $1 b$

Figure 1. A sample musical excerpt illustrating normal spacing (1a) and disrupted spacing (1b).

Results

Separate 2-way ANOVA were performed to determine if specific effects existed between expert and non-expert music sight-readers when music score was disrupted and significance was assigned at the 0.05 level. The results were summarized in Figure 2. Normal and Disrupted Score were plotted against Total Time (Figure 2a), Number of Fixations (Figure 2b), Total Fixation Duration (Figure 2c), Fixation Duration minus Saccadic Latency (Figure 2d), Saccadic Latency (Figure 2d), Number of Forward Saccades (Figure 2e), Forward Saccade Speed (Figure 2g), Number of Regressive Saccades (Figure 2h) and Regressive Saccade Speed (Figure 2i) when performing musical excerpts from T1 to T2 for expert and non-expert music sight-readers. Error bars = SEM.

\section{Total Time}

The results revealed a significant effect of expertise; $\mathrm{F}$ $(1,40)=28.16, p<0.0001$. Expert sight-readers performed significantly faster than non-experts over both conditions. There was no significant interaction between score disruption and expertise for time; $\mathrm{F}(1,40)=0.025, \mathrm{p}=0.88$.

\section{Number of Fixations}

No significant expertise effect: $F(1,38)=1.870, p=0.18$ or interaction between score disruption and expertise were found: $\mathrm{F}(1,38)=0.17, \mathrm{p}=0.68$.

\section{Saccadic latency}


No overall expertise effect was found for score disruption: $\mathrm{F}(1,39)=0.48, \mathrm{p}=0.49$. However, the disruption in score caused the expert group to have a significant increase in saccadic latency: $F(1,7)=2.82, p=0.03$, while the nonexperts showed little change.

\section{Fixation Duration}

The saccadic latencies were subtracted from the duration measure from the eye tracker. No general expertise effects were found: $F(1,39)=0.27, p=0.61$ and no interaction between expertise and score disruption was found for FD: $\mathrm{F}(1,39)=0.06, \mathrm{p}=0.80$.

\section{Number of Forward Saccades}

No general expertise effects were found: $F(1,38)=1.49$, $\mathrm{p}=0.23$ and no interaction between expertise and score disruption was found for the number of forward saccades: $\mathrm{F}(1,38)=0.15, \mathrm{p}=0.70$.

\section{Number of Regressive Saccades}

Regressive saccades behaved in a similar fashion to forward saccades showing no significant expertise effects: $F$ $(1,38)=2.28, \mathrm{p}=0.14$ and no interaction between expertise and score disruption was found: $\mathrm{F}(1,38)=0.27, \mathrm{p}=$ 0.60 .

\section{Forward Saccade Speed}

No general expertise effects were found: $F(1,38)=1.13$, $p=0.29$ and no interaction between expertise and score disruption was found for the number of forward saccade speed: $F(1,38)=0.01, p=0.92$.

\section{Regressive Saccade Speed}

In a similar fashion, no general expertise effects were found: $F(1,38)=2.24, p=0.14$ and no interaction between expertise and score disruption was found for the number regressive saccade speed: $F(1,38)=9.45, p=0.99$.

In summary, expert sight-readers performed significantly faster than non-experts: $\mathrm{p}<0.0001$. Score disruption had no significant effect on the Total Time within either group. Saccadic latency was the only other measure to reach significance and this was for experts only when encountering disrupted score - the latency increased significantly: $\mathrm{p}=$ 0.03 .

\section{Discussion}

The Total Time taken to perform from T1 to T2 was unaffected by disruption to the music score for either group. However, the expert group was significantly faster overall and the two groups employed different strategies in order to maintain their speed of performance despite the disruption of the score. This may be explained by comparing sight-readers with typists. It was found that their self-selected speed to ensure accuracy was somewhat conservative and approximately 10-20\% below potential (Ericsson et al., 2007). Therefore, each group may have been performing well below their absolute limit in the initial playing and the score disruption was insufficient to impact upon their total time.

Previous research has found that, when reading text, Fixation Duration increases when targets are visually disrupted (Staub, 2013). The Total Fixation Duration was found to increase in this study, though not significantly for either group in either condition (see Figure 2c). However, when the saccadic latency is taken into account the results tell a different story.

The expert music sight-readers were affected by the disruption and this was shown by their significant increase in saccadic latency: $p=0.03$ (see Figure $2 d$ ). This finding is in agreement with previous studies on text reading (Cameron, 1995) but did not appear to be the case for non-expert music sight-readers. This may be due to the fact that when testing eye movements on text readers, the participants are adults and exhibit expertise for text reading. The Cameron, 1995 study did not explore the saccadic latency in novice text readers to facilitate comparison with text reading experts. The current study participants were all adults, but only some with expertise in sight-reading. The only significant result was the saccadic latency change in the experts. Perhaps an easier reading task for the non-experts that is then disrupted might show a significant latency change. However, opinion is divided on the relationship between fixations and saccades.

Some researchers have suggested that uncertainty causes saccade cancellation and increased fixation duration (Perea \& Acha, 2009, Yang \& McConkie, 2001). Others advocate that the response to uncertainty is for longer latencies with fewer and shorter saccades (Cameron, 1995; Kowler \& Anton, 1987). The results from the current study appear to agree with the latter model for the experts, as a significant increase in latency was found. However, no firm conclusions can be drawn regarding the non-expert group due to the large within group variability. Nevertheless, the non-experts do not appear to adopt the saccade cancellation strategy just to be different from the experts. Rather, they appear to consolidate their 'novice' actions by increasing the number of saccades with shorter duration fixations, but no parameters were significant. Neither group showed an increase in regressive saccades. This was a notable variation from text reading literature where experts increased regressive saccades with uncertainty in the text (Rayner et al., 2006). This this may be due to the task not being difficult enough to elicit such a response or a 
Total Time T1:T2

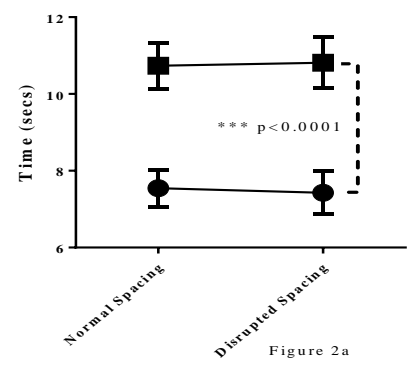

Fixation Duration

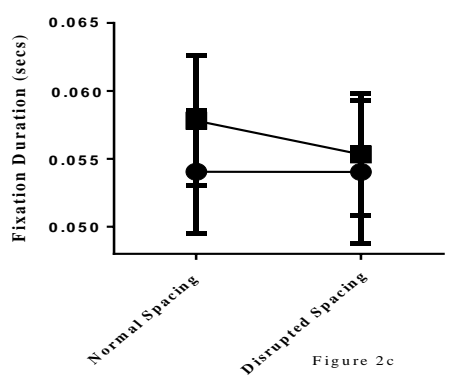

Legend: $\quad$ Expert Sight Readers

- Non-Expert Sight Readers
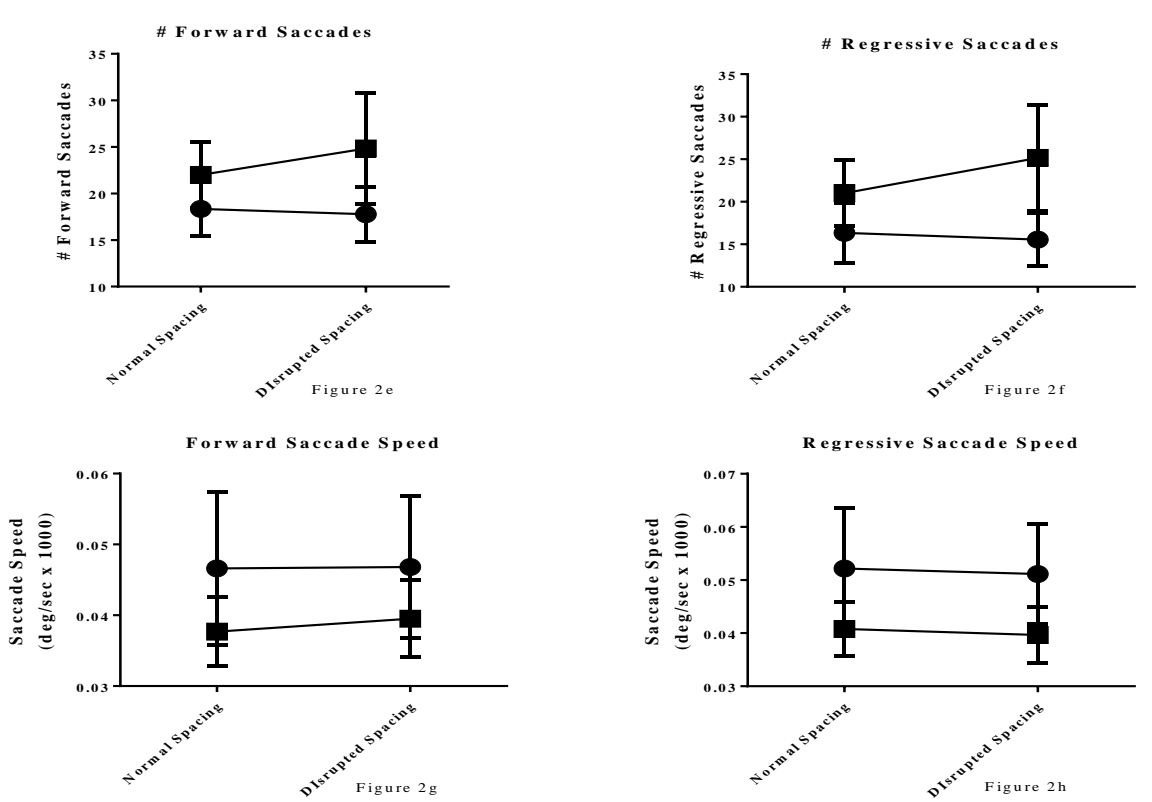

Figure 2: Normal and Disrupted Spacing plotted against Total Time (Figure 2a), Number of Fixations (Figure 2b), Fixation Duration (Figure 2c), Saccadic Latency (Figure 2d), Number of Forwrd Saccades (Figure 2e), Number of Regressive accades (Figure 2f) Forward Saccade Speed (Figure 2g, and Regressive Saccade Speed (Figure 2h) when performing musical excerpts from T1 to T2 for expert and non-expert music sight readers. Error bars = SEM. 
fundamental difference in how meaning is assigned when reading text as compared with reading music score.

For example, punctuation in text is essential for the reader to understanding meaning. Removing key elements of punctuation completely alters the meaning of a sentence, even though the same words may be used in exactly the same order. For example, the sentence, "Go and eat, Grandma," does not mean the same thing as "Go and eat Grandma." The absence of the comma between 'eat' and 'grandma' changes the sentence from an appeal for Grandma to have a meal to a request for someone to have Grandma as the meal! In the context of music generally, the bar line acts as a temporal marker: notes and rests between bar lines must conform to the note count indicated! In the context of music generally, the bar line acts as a temporal marker: notes and rests between bar lines must conform to the note count indicated by the time signature at the beginning of the music. Removing the bar line does not alter that 'meaning' of the group of notes; unlike the sentence above. A minim followed by a crotchet followed by two quavers is a group whether or not they are separated by a bar lines or not.

Altering the space between the notes or the direction of the beam also does not alter note pitch or duration, it is merely incorrectly notated in the context of a single melodic line of music. This may in turn impact upon a musician's automaticity of processing as the note spacing does not correspond with the notated duration or the beam with the pitch of the notes on the stave. It is not unreasonable, therefore, that the experts were able to play relatively unperturbed by such visual disruptions expect for an increase in saccadic latency because they were not grouped in a predictable manner. Similarly, the non-experts became more 'non-expert' by showing a general increase in eye movement activity. Regardless, having shown that there is a different eye movement response between the two groups, can this be attributed to the key delineator of expertise - Working Memory Capacity (Hambrick, Altmann, Oswald, Meinz, Gobet, \& Campitelli, 2014; Meinz \& Hambrick, 2010) and the cross modal nature of music reading (Drai-Zerbib \& Baccino, 2014; Drai-Zerbib, Baccino, \& Bigland, 2012, Meyer \& Wuerger, 2001; Wong \& Gauthier, 2009)?

The working memory model developed by (Baddeley \& Hitch, 19874) proposes that short-term visual and shortterm auditory holding facility are processed by the 'visuospatial sketch-pad' and the 'phonological loop' memory stores, respectively. It is from these stores that information can be processed by the 'central executive'. This differed from other theories of the time which held that there was a Short Term Memory facility that fed directly into Long Term Memory (Atkinson \& Shiffrin, 1968). Baddeley and Hitch's model differed by the addition of a 'working memory' that could process using information from these short-term stores without necessarily involving long term memory. Their key findings related to the capacity and interactions between these two storage systems and the central executive.

Regarding cross-modal integration of music stimuli, it has been shown that musicians initially convert a visual stimulus unto an auditory modality for retrieval (Simoens \& Tervaniemi, 2013). This may involve the phonological loop and Baddeley has suggested that maintaining information in the phonological loop requires fewer attentional reserves (Baddeley, 2007). Baddeley further suggests, on page 19 of chapter 11 , that very familiar objects are subject to being 'cleaned up' during storage in the loop by accessing stored knowledge. This is unlike the visuospatial short term memory which is likely to be more involved with the processing of novel material and requires more conscious attention (Baddeley, 2007). Therefore, disruption of the excepted patterns of music score may be impeding the conversion of visual stimuli to auditory storage and/or confounding the 'clean up' process because the visual presentations do not conform to existing knowledge. That is, the central executive is required to devote more conscious attention to the disrupted score because information is more difficult to store in the phonological loop. This may explain the increase in latency observed in the expert group - there is a disruption to working memory due to the uncertainty that has been created (Cameron, 1995). Another study found that experts gazed longer at the score when there was a mismatch between the auditory and visual stimuli suggesting an interruption to cross-modal integration (Drai-Zerbib \& Baccino, 2014).

Perhaps experts' less crowded peripheral vision for musical notes (Wong \& Gauthier, 2012) was somehow sabotaged by the unexpected spaces and inappropriate structures in the field of view. Irrespective of the exact etiology of the problem, the chunking mechanisms were interrupted for the experts and this was evidenced by an increase in saccadic latency. Future inquiries introducing greater visual complexity and disruption to the normality of the score - such as the inclusion of unexpected, non-musical symbols and the individual review of space, bar lines and beaming - might shine further light on the nature of interference effects in relation to expertise and music reading processes in general. The more extreme the disruption, the more the expert sight-readers may not be able to maintain their normal processing strategies. They may begin to show more of a note by note approach in order to maintain an effectual performance. This was shown to be the case for expert violinists when the score was visually complex rather than predictable (Wurtz et al., 2009). In addition, assessing the specific effects of note spacing or the removal of bar lines or changing the beam direction might individ- 
ually have on EM patterns may more concisely demonstrate the nature of the visual interference responsible for affecting processing efficiency. Such findings may help to further understand the cognitive relationships between text and music reading.

The disrupted condition found the non-experts executing more forward saccades at a faster speed than the experts. While this result was not significant, it is a somewhat counterintuitive finding considering that experts are said to look ahead more when sight-reading music. The act of looking ahead has been shown to be more efficient for expert sight-readers and has more to do with 'chunking' a greater amount of visual information into a single fixation than consciously looking ahead as an attempt to gather more information (Sloboda, 1985).

Previous studies have shown that object identification can be attained following a fixation of as little as $80-100 \mathrm{~ms}$ duration (Salthouse \& Ellis, 1980). As technology has improved and/or the ability to measure and account for the noise in the system, the figure has diminished $-50 \mathrm{~ms}$ (Rayner, 1998) and 40ms (Nystrom \& Holmqvist, 2010). The current study was not sufficiently sensitive to detect such small fixation durations. The role of these micro fixations has yet to be determined in relation to visual processing expertise and may yield valuable insights into differing processing strategies. Utilizing greater amounts of visual disruption in order to generate more visual processing uncertainty, along with more sensitive settings to detect variations in the durations of fixations, would be necessary to further investigate the differences between expert and non-expert music sight-readers.

The aim of the current study was to detect differences in eye movement patterns when unexpected visual presentations of music score are read by expert and non-expert music sight-readers. Saccadic latency measures between trials for the expert group was the only significant finding from this study. It is a particularly interesting result as it occurred on their second pass reading. This might not be expected if the first pass reading is so important in this context as the visual disruptions seemed to affect the experts more than any familiarity that might have resulted from the first pass reading. Measuring of first and second pass EMs for each group and each condition separately in future studies would help to clarify this point.

Aspects of working memory, cross-modal integration and peripheral visual processing have been proposed as possible mechanisms to account for this. Whether these eye movement responses involve similar cognitive processes as those related to unexpected harmonic structures is an interesting subject for future investigation.

\section{Conclusion}

Visual disruption of the music score, as expected, significantly affected the eye movement patterns of expert sightreaders. This was demonstrated by a significant increase in saccadic latency showing that their ability to recognize note grouping had been compromised by the unexpected and unusual patterns in the notation.

The non-experts showed some generalized disturbance of their eye movement patterns: mainly more frequent fixations of shorter duration. None of these reached significance and suggest that the non-expert group maintained their more note-by-note visual processing strategy in this study.

\section{Acknowledgements}

This research was supported by the Australian Research Council project grant (DP11010471) to S Khuu and The Australian Postgraduate Award to Patricia Arthur.

The authors declare that there is no conflict of interest regarding the publication of this paper.

\section{References}

Ashby, J., Rayner, K. \& Clifton, C. (2005). Eye movements of highly skilled and average readers: differential effects of frequency and predictability. The Quarterly journal of experimental psychology., 58(6), 1065-1086. http://dx.doi.org/10.1080/02724980443000476

Atkinson, R. C. \& Shiffrin, R. M. (1968). Human memory: A proposed system and its control processes. The psychology of learning and motivation: advances in research and theory, (Vol. 2, pp. 89-195). New York: Academic Press. http://dx.doi.org/10.1016/S00797421(08)60422-3

Baddeley, A. (2007). Working memory, Thought, and Action. Oxford: Oxford University Press. http://dx.doi.org/10.1093/acprof:oso/978019852 8012.001 .0001

Baddeley, A. \& Hitch, G. (1974). Working Memory. The Psychology of Learning and Motivation, 8.

Balota, D. A., Pollatsek, A. \& Rayner, K. (1985). The interaction of contextual constraints and parafoveal visual information in reading. Cognitive Psychology, 17(3), 364-390.

Banton, L. (1995). The role of visual and auditory feedback during the sight-reading of music. Psychology of Music, 23, 3-16. 
Bilalic, M., Langner, R., Ulrich, R. \& Grodd, W. (2011). Many faces of chess expertise: Fusiform face area in chess experts and novices. The Journal of Neuroscience, 31(28), 10206-10214. http://dx.doi.org/10.1523/JNEUROSCI.572710.2011

Binder, K. S., Pollatsek, A. \& Rayner, K. (1999). Extraction of information to the left of the fixated word in reading. Jouranl of Experimental Psychology and Human Perceptual Performance, 25(4), 1162-1172.

Cameron, E. L. (1995). Factors Determining the Latency of Saccadic Eye Movements. (PhD), University of Rochester, New York.

Dee-Lucas, D., Just, M. A., Carpenter, P. \& Daneman, M. (1982). What Eye Fixations tell us about time course if text integration. In R. Groner \& P. Fraisse (Eds.), Cognition and Eye Movements, 155-168. Amsterdam: North Holland Publishing Company.

Drai-Zerbib, V. \& Baccino, T. (2014). The effect of expertise in music reading: cross-modal competence. Journal of Eye Movement Research, 6(5), 1-10. http://dx.doi.org/10.16910/jemr.6.5.5

Drai-Zerbib, V., Baccino, T. \& Bigand, E. (2012). Sightreading expertise: Cross-modality integration investigated using eye tracking. Psychology of Music, 40(2), 216-235.

http://dx.doi.org/10.1177/0305735610394710

Ehrlich, S. \& Rayner, K. (1981). Contextual Effects on Word Perception and Eye Movements during Reading. Journal of Verbal Learning and Verbal Behaviour, 20, 641-655.

Ericsson, K. A., Krampe, R. T. \& Tesch-Romer, C. (1993). The role of deliberate pracrice in the aquisition of expert performance. Psychology Review, 100(3), 363-406.

Ericsson, K. A., Roring, R. \& Nandagopal, K. (2007). Giftedness and evidence for reproducibly superior performance: An account based on the expert performance framework High Ability Studies, 18(1), 3-56. http://dx.doi.org/10.1080/13598130701350593

Farrington-Darby, T. \& Wilson, J. (2006). The nature of expertise: A review. Applied Ergonomics, 37, 17-32. http://dx.doi.org/10.1016/j.apergo.2005.09.001

Fleisher, A. G. (1986). Control of Eye Movements by Working Memory Load. Biological Cybernetics, 55, 227-238.

Fourie, E. (2004). The processing of music notation: some implications for piano sight-reading.
Journal of the Musical Arts in Africa, 1(1), 1-23. http://dx.doi.org/10.2989/18121000409486685

Furneaux, S. \& Land, M. F. (1999). The effects of skill on the eye-hand span during musical sightreading. Proceedings: Biological Sciences, 266(1436), 2435-2440. http://dx.doi.org/10.1098/rspb.1999.0943

Gauthier, I. \& Bukach, C. (2007). Should we reject the expertise hypothesis? Cognition, 103, 322-330. http://dx.doi.org/10.1016/j.cognition.2006.05.00 $\underline{3}$

Gobet, F., Lane, P. C., Croker, S., Cheng, P. C., Jones, G., Oliver, I. \& Pine, J. M. (2001). Chunking mechanisms in human learning. Trends in Cognitive Science, 5(6), 236-243. http://dx.doi.org/10.1016/S13646613(00)01662-4

Goolsby, T. (1987). The Parameters of Eye Movements in Vocal Music Reading. ProQuest Dissertations and Theses.

Goolsby, T. (1994). Eye Movement in Music Reading: Effects of Reading Ability, Notational Complexity, and Encounters. Music Perception: An Interdisciplinary Journal, 12(1), 77-96. http://dx.doi.org/10.2307/40285756

Hambrick, Oswald, F., Altmann, E., Meinz, E., Gobet, F. \& Campitelli, G. (2014). Deliberate practice: Is that all it takes to become an expert? Intelligence, 45, 34-45. http://dx.doi.org/ 10.1016/j.intell.2013.04.001

Heller, D. (1982). Eye Movements in Reading. In R. a. F. Groner, P. (Ed.), Cognition and Eye Movements (pp. 139-154). Amsterdam: North Holland Publishing Company.

Huron, D. (2001). Is music an evolutionary adaptation? Annals of the New York Academy of Sciences, 930, 43-61.

Juhasz, B. J. \& Rayner, K. (2003). Investigating the effects of a set of intercorrelated variables on eye fixation durations in reading. Journal of experimental psychology: Learning, memory, and cognition, 29(6), 1312-1318. http://dx.doi.org/10.1037/0278-7393.29.6.1312

Just, M. A. \& Carpenter, P. A. (1976). Eye Fixations and Cognitive Processes. Cognitive Psychology, 8, 441-480.

Kennison, S. M. \& Clifton, C., Jr. (1995). Determinants of parafoveal preview benefit in high and low working memory capacity readers: implications for eye movement control. Journal of experimental psychology: Learning, memory, and cognition, 21(1), 68-81. 
Kinsler, V. \& Carpenter, R. H. S. (1995). Saccadic eye movements while reading music. Vision Research, 35(10), 1447-1458. http://dx.doi.org/10.1016/0042-6989(95)98724$\mathrm{N}$

Kowler, E. \& Anton, S. (1987). Reading Twisted Text: Implications for the role of Saccades. Vision Research, 27(1), 45-60.

Kowler, E. (2011). Eye movements: the past 25 years. Vision Res, 51(13), 1457-1483. http://dx.doi.org/10.1016/j.visres.2010.12.014

Legge, G. E. (2007). The Psychophysics of Reading. New Jersey, USA: Lawrence Erlbaum Associates, Inc.

Lehmann, A. \& McArthur, V. (2002). Sight-reading. In R. Parncutt \& G. McPherson (Eds.), The Science \& Psychology of Music Performance: Creative Strategies for Teaching and Learning, (pp. 135150). Oxford: Oxford University Press. http://dx.doi.org/10.1093/acprof:oso/978019513 8108.001 .0001

Madell, M. \& Hebert, S. (2008). Eye Movements and Music: Where do we Look Next? Music Perception, 26, 157-170.

Meinz, E., \& Hambrick, D. (2010). Deliberate Practice Is Necessary but Not Sufficient to Explain Individual Differences in Piano Sight-Reading Skill: The Role of Working Memory Capacity. Psychological Science, 21(7), 914-919. http://dx.doi.org/10.1177/0956797610373933

Meseguer, E., Carreiras, M. \& Clifton, C., Jr. (2002). Overt reanalysis strategies and eye movements during the reading of mild garden path sentences. Memory \& Cognition, 30(4), 551561.

Meyer, G. \& Wuerger, S. (2001). Cross Modal Integration of Auditory and Visual Motion Signals. Neuroreport, 12(11), 2557-2560.

Miellet, S. \& Sparrow, L. (2004). Phonological codes are assembled before word fixation: evidence from boundary paradigm in sentence reading. Brain \& Language, 90(1-3), 299-310. http://dx.doi.org/10.1016/S0093934X(03)00442-5

Nystrom, M. \& Holmqvist, K. (2010). An adaptive algorithm for fixation, saccade, and glissade detection in eyetracking data. Behaviour Research Methods, 42(1), 188-204. http://dx.doi.org/ 10.3758/BRM.42.1.188

Perea, M. \& Acha, J. (2009). Space information is important for reading. Vision Research, 49(15), 1994-2000. http://dx.doi.org/10.1016/j.visres.2009.05.009
Rayner, K. (1998). Eye movements in reading and information processing: 20 years of research. Psychological Bulletin, 124(3), 372-422. http://dx.doi.org/10.1037/0033-2090.124.3.372

Rayner, K., Chace, K., Slattery, T. \& Ashby, J. (2006). Eye Movements as Reflections of Comprehension Processes in Reading. Scientific Studies of Reading, 10(3), 241-255. http://dx.doi.org/10.1207/s1532799xssr1003 3

Rayner, K., Fischer, M. \& Pollatsek, A. (1998). Unspaced text interferes with both word identification and eye movement control. Vision Research, 38(8), 1129-1144. http://dx.doi.org/10.1016/S00426989(97)00274-5

Restle, F. (1972). Serial Patterns: The Role of Phrasing. Journal of Experimental Psychology, 92(3), 385-390. http://dx.doi.org/10.1037/h0032272

Salthouse, T. \& Ellis, C. (1980). Determinants of Eye Fixation Duration. The American Journal of Psychology, 93(2), 207-234.

Schmidt, F. (1981). Movement Patterns of Woodwind Instrument Performers while Sight Reading Music. Proquest Dissertations and Theses.

Servant, I. \& Baccino, T. (1999). Lire Beethoven : une étude exploratoire des mouvements des yeux Muslcae Scientiae, 3(1), 67-94.

Simoens, V. \& Tervaniemi, M. (2013). Auditory ShortTerm Memory Activation during Score Reading. PLoS ONE, 8(1), 1-10. http://dx.doi.org/10.1371/journal.pone.0053691

Sloboda, J. (1974). The Eye-Hand Span: An Approach to the Study of Sight Reading. Psychology of Music, 2(4), 4-10.

Sloboda, J. (1976). Visual percpetion of musical notation: registering pitch symbols in memory. Quarterly Journal of Experimental Psychology, 28(1), 116.

Sloboda, J. (1977). Phrase Units as Determinants of Visual Processing in Music Reading. British Journal of Psychology, 68, 117-124.

Sloboda, J. (1985). The Musical Mind: The Cognitive Psychology of Music. Oxford: Clarendon Press.

Staub, A. \& Benetar, A. (2013). Individual differences in fixation duration distributions in reading. Psychonomic Bulletin \& Review, 20, 1304-1311. http://dx.doi.org/10.3758/s13423-013-0444-X

Truitt, F., Clifton, C. J., Pollatsek, A. \& Rayner, K. (1997). The Perceptual Span and the Eye-Hand Span in Sight Reading Music. Visual Cognition, 4(2), 143-161. http://dx.doi.org/10.1080/713756756

Underwood, G., Hubbard, A. \& Wilkinson, H. (1990). Eye fixations predict reading comprehension: 
the relationships between reading skill, reading speed, and visual inspection. Language \& Speech, 33 ( Pt 1), 69-81.

Waters, A. J., Townsend, E, \& Underwood, G. . (1998). Expertise in musical sight reading: a study of pianists. British Journal of Psychology, 89(1), 123-149.

Wolf, T. (1976). A cognitive model of musical sightreading. Journal of Psycholinguist Research, 5(2), 143-171 http://dx.doi.org/10.1007/BF01067255

Wong, Y. K. \& Gauthier, I. (2009). A Multimodal Neural Network Recruited by Expertise with Musical Notation. Journal of Cognitive Neuroscience, 22(4), 695-713.
Wong, Y. K. \& Gauthier, I. (2012). Music-reading expertise alters visual spatial resolution for musical notation. Psychonomic Bulletin \& Review, 19(4), 594-600. http://dx.doi.org/10.3758/s13423-012-0242-x

Wurtz, P., Mueri, R. \& Wiesendanger, M. (2009). Sightreading of violinists: eye movements anticipate the musical flow. Experimental Brain Research, 194(3), 445-450.

http://dx.doi.org/10.1007/s00221-009-1719-3

Yang, S.-N. \& McConkie, G. W. (2001). Eye movements during reading: a theory of saccade initiation times. Vision research, 41, 3567-3585. 